\title{
An Adaptive Throttle and Brake Control System for Automatic Cruise Control in Disability Support Vehicle
}

\author{
G. Lavanya \\ Department of Information \\ Technology \\ Sri Krishna College of Technology \\ Coimbatore, Tamil Nadu, India. \\ g.lavanya@skct.edu.in
}

\author{
M. Deva Priya \\ Department of Computer \\ Science \& Engineering \\ Sri Krishna College of Technology \\ Coimbatore, Tamil Nadu, India. \\ m.devapriya@skct.edu.in
}

\author{
A. Balamurugan \\ Department of Computer \\ Science \& Engineering \\ Sri Krishna College of Technology \\ Coimbatore, Tamil Nadu, India. \\ a.balamurugan@skct.edu.in
}

\author{
A. Christy Jeba Malar \\ Department of Information \\ Technology \\ Sri Krishna College of Technology \\ Coimbatore, Tamil Nadu, India. \\ a.christyjebamalar@skct.edu.in
}

This is in response to observing certain faults which are to be rectified. For a better understanding, we want to make minor changes in the original paper.

In Section 3.2 Anti-Lock Braking System (ABS), there is a mistake in the citation.

An Anti-lock Braking System (ABS) is designed for the safety of motor vehicles. This system permits the wheels of a motor vehicle to maintain frictional contact with the road surface based on the driver inputs. Braking prevents locking of wheels which occur when their rotation halts suddenly (Thakur and Thakare 2015).

In Section 5. IMPLEMENTATION AND RESULTS, variable ' $\mathrm{S}_{\mathrm{b}}$ ' is mentioned twice. One has to be replaced by ' $\mathrm{S}_{\mathrm{e}}$ '.

$\mathrm{S}_{\mathrm{e}} \quad$ - Distance travelled from a location based on ' $\mathrm{V}_{\mathrm{o}}$ ' to a location based on ' $V$ ' in ' $m$ '

In the reference Section, Reference 1 is not cited in the text and hence can be removed. 